\title{
Dose Efficiency in Dual Source High-Pitch Computed Tomography of the Chest
}

\author{
Boris Bodelle, Thomas Lehnert, Martin Beeres, Thomas Josef Vogl, Boris Schulz \\ Department of Diagnostic and Interventional Radiology, Clinic of the Goethe University, \\ Frankfurt, Germany \\ Email: bbodelle@googlemail.com
}

Received 21 October 2014; revised 17 November 2014; accepted 24 November 2014

Copyright $@ 2014$ by authors and Scientific Research Publishing Inc.

This work is licensed under the Creative Commons Attribution International License (CC BY).

http://creativecommons.org/licenses/by/4.0/

(c) (i) Open Access

\section{Abstract}

Objectives: Evaluation of radiation efficiency of dual source high-pitch (DSHP) chest CT in comparison to single source technique with special regards to individual patient anatomy. Methods: 150 consecutive patients who underwent chest $C T$ with automated tube current modulation were evaluated retrospectively and divided into three study groups, each with an equal quantity of $\mathbf{5 0}$ patients (DSHP vs. single source 128 slices vs. single source 16 slices). By using a dedicated workstation, volumetric analyses of each of the scanned anatomic area were performed and correlated to the individual dose length product (DLP). The calculated result was defined as dose efficiency. Results: DLP was 203 mGycm (DSHP), vs. 269 mGycm (single source) vs. 273 mGycm (16 slice CT). The total patient volume was lowest in the dual source group with $18956.3 \mathrm{~cm}^{3}$ (vs. $22481.2 \mathrm{~cm}^{3}$ vs. $22133.8 \mathrm{~cm}^{3}$ ). With regards to the DLP, the calculated dose efficiency of dual source CT was better than the 128 slice CT $(p=0.045)$ and the 16 slice CT $(p<0.01)$. Conclusions: DSHP CT has considerably better dose efficiency compared to 16 slice CT. Compared to 128 slice single source technique, the high-pitch mode does not cause any dose penalty when performing chest CT.

\section{Keywords}

Computed Tomography, Lung, Radiation Exposure, Imaging, Dual-Source

\section{Introduction}

Multislice computed tomography (CT) is the current standard imaging modality for the in-depth and simultaneous assessment of the anatomy and pathology of thoracic organs, vessels and associated osseous structures. This examination is usually performed using a breath-hold technique to minimize respiratory motion artifacts, which

How to cite this paper: Bodelle, B., Lehnert, T., Beeres, M., Vogl, T.J. and Schulz, B. (2014) Dose Efficiency in Dual Source High-Pitch Computed Tomography of the Chest. Advances in Computed Tomography, 3, 51-58. 
is a basic requirement of a diagnostically conclusive dataset. In addition, in recent years the number of detector rows in the z-axis (longitudinal) direction has been increased, permitting greater anatomic coverage in a single gantry rotation and thus reducing the breath-hold time [1]. Recently, CT devices with two x-ray tubes have been introduced that can be used simultaneously for the examination (dual-source technology) [2]. The second tube, which is shifted by about $90^{\circ}$, then fills gaps that occur when pitch values exceed 1.5. By the use of this technique, a gapless dataset of a chest CT study can be obtained in less than a second, essentially eliminating any motion artifacts while maintaining diagnostically conclusive image quality [3]-[6]. Recent literature shows a comparable or decreased radiation dose when using the dual-source high-pitch (DSHP) examination technique for cardiac or pulmonary angiography CT studies which focus on limited parts of the thorax [7]-[10]. However, radiation exposure of DSHP CT is unknown for whole chest examinations since the amount of irradiated volume of lung parenchyma and soft tissue vary sharply among each patient and only slim patients can be examined with the DSHP mode. This is due to the fact that the maximum transverse field of view is technically limited to a diameter of $33 \mathrm{~cm}$. The purpose of this study is to analyze the patient radiation exposure of single and dualsource chest CT with regard to the influence of individual volumetric characteristics of the examined patients.

\section{Material and Methods}

\subsection{Study Group and Examination Technique}

A dataset of 150 different adult patients who underwent thoracic CT with three different CT techniques between January and June 2010 was analyzed retrospectively for this study. The study was approved by the institutional review board. Each group consisted of 50 consecutive patients that were each examined using dual and single-source techniques at equal tube voltage and current settings. The dual-source group was examined with a CT device capable of a pitch value of 3.0 (Somatom Definition Flash, Siemens Health Care, Erlangen, Germany). The other study groups were examined in single source 128 slice technique on the same CT device, the third group was examined in a 16 slice device (Somatom Sensation 16, Siemens Health Care, Germany, Erlangen) (see Table 1 for detailed examination parameters). Automated tube current modulation (CARE Dose 4DTM, Siemens Health Care, Erlangen, Germany) was activated by default in all groups. This technique mainly uses the previously generated scout view to assess necessary tube currents of each slice to minimize "radiation exposure" of regions with low density tissue or air filled spaces, such as lung parenchyma. Exclusion criteria for the study were patients with implanted metal devices, since these interfere inconsistently with automated tube current modulation and cause beam hardening artifacts. The patients included in this study did not receive any intravenous or oral contrast material.

\subsection{Volume Measuring Techniques, Radiation Exposure, Image Noise}

To correlate applied radiation dose to individual patient morphology, anatomic evaluation of each CT study was performed on a multimodality workstation (Advantage Workstation-Suite, GE Healthcare, Barrington, USA). By performing volumetric measurements of each examination we could assess the radiation exposure for each

Table 1. Examination preferences of dual and single-source chest CTs. Tube current is given as "mAseff”, since the activated tube current modulation technique (CARE Dose 4D) was activated by default.

\begin{tabular}{cccc}
\hline & Group 1 & Group 2 & Group 3 \\
\hline Tube voltage/tube current & & $120 \mathrm{kVp} / 110 \mathrm{mAs}_{\text {eff }}$ & \\
\hline No. of detector layers & $2 \times 128$ & 128 & 16 \\
Collimation & $0.6 \mathrm{~mm}$ & $0.6 \mathrm{~mm}$ & $0.5 \mathrm{sec}$ \\
Rotation time & $0.28 \mathrm{sec}$ & $0.5 \mathrm{sec}$ & 1.2 \\
Pitch value & 3.0 & 1.2 & $50 \mathrm{~cm}$ \\
\hline
\end{tabular}


individual. This approach can provide the actual radiation dose for each patient rather than simply the doselength product (DLP). For detailed volumetric analyses the lung volume and surrounding tissue were evaluated separately (Figure 1). The examined total patient volume was measured by manually contouring the skin borders on every third slice with a segmentation tool (Advantage Workstation-Suite Cutting Tool, GE Healthcare, Barrington, USA); the interspaces were then interpolated by the software and the result was recorded. To separate lung parenchyma, automated segmentation with a range of -1024 Hounsfield units (HU) to -150 HU was performed. Finally, the soft tissue and bone volume could be calculated by subtracting the lung volume from total patient volume. Image processing was performed on $5 \mathrm{~mm}$ axial images with an edge-enhancing "lung" kernel (B60) that were reconstructed from the primary dataset (raw data). The estimation of radiation exposure was performed by using the DLP given in $\mathrm{mGy} \times \mathrm{cm}$. The DLP was stored in the picture archiving system in a tabulated form after each examination. Correlations of the DLP to patient volume, separate lung volume, bone volume and soft tissue volume were calculated. In a final step the mathematical quotient of the volume with the highest correlation to the DLP was used for comparison of normalized radiation exposure (dose efficiency) of each study group. This parameter represents the scanned volume per DLP, thereby the anatomically adjusted photon efficiency of each CT device. A higher value represents the result of an increased photon yield, since the examined area would be higher per DLP.

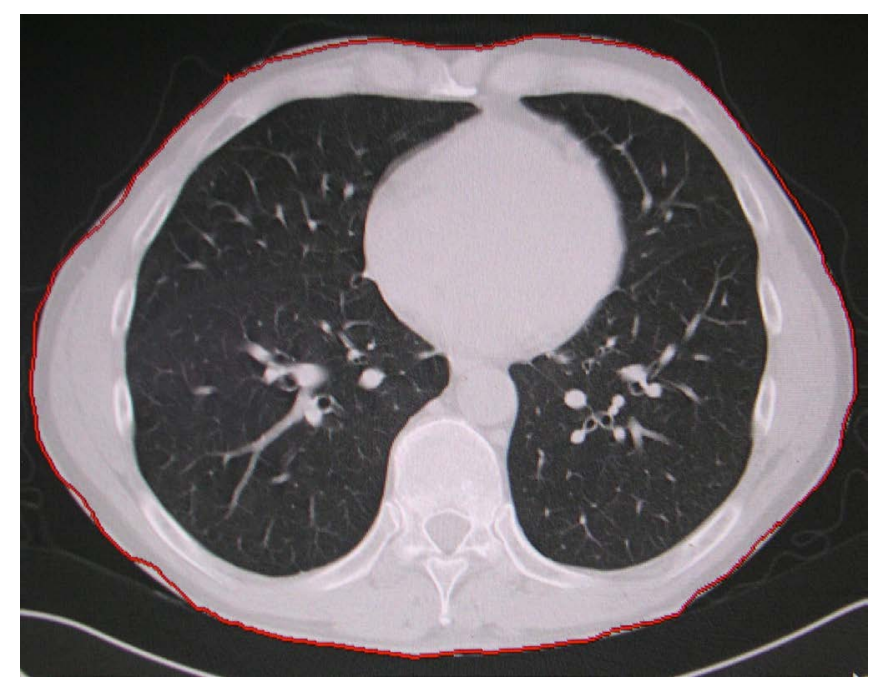

(a)

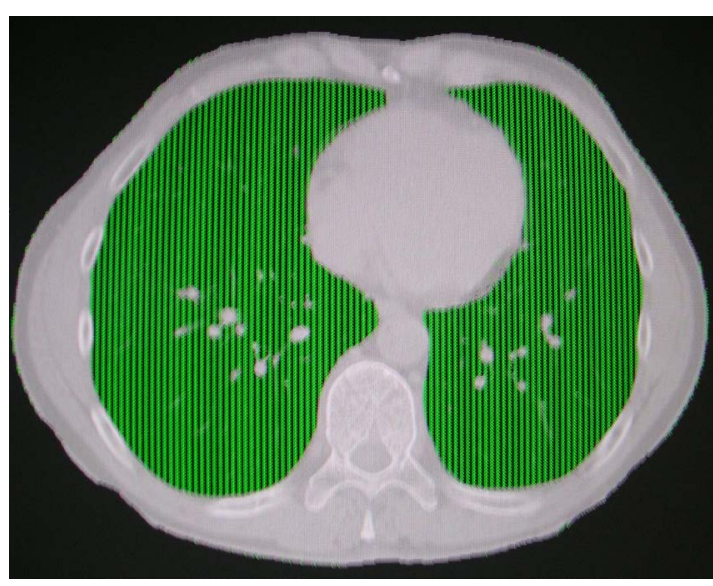

(b)

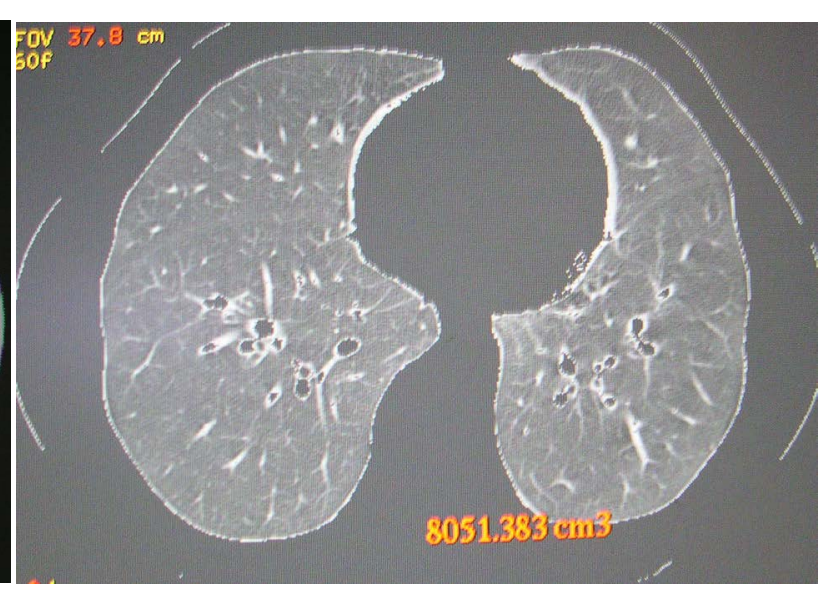

(c)

Figure 1. (a) Detailed volume measurements: Firstly, the total patient volume was defined by manually cutting out the body limits (a). Then the lung volume was separated using an automatic threshold function of -300 to -1024 Hounsfield Units; (b) and (c) Lung volume separation using an automatic threshold function of -300 to -1024 Hounsfield Units. 


\subsection{Statistical Analyses}

Statistical analyses of independent groups were performed using the Wilcoxon-Mann-Whitney U-test to analyze differences in means with a significance level of $p<0.05$. Correlations were calculated to examine dependency of the variables to the DLP using the Spearman's rank correlation coefficient due to the assumption that normality was not satisfied. Calculations were performed using the software SPSS (V15.0, IBM Corporation, New York, USA).

\section{Results}

The demographics were similar in all groups: Mean age was 55.7 years with standard deviation of 14.3 years (dual-source group) versus 59.1 years (14.8 years standard deviation, 128 slice CT group) versus 58.4 years (15.6 years standard deviation, 16 slice CT group), while the female-to-male ratios were 21:29, 19:31, and 24:26, respectively. The average radiation exposure in terms of DLP was significantly lower (max. $-25 \%$ ) when using the DSHP CT technique with $204 \mathrm{mGy} \times \mathrm{cm}(\min : 121 \mathrm{mGy} \times \mathrm{cm}$, max: $275 \mathrm{mGy} \times \mathrm{cm}$, median: $212 \mathrm{mGy} \times$ $\mathrm{cm}$ ) in comparison to both of the other techniques ( $<<0.001$, Figure 2). Both single source techniques yielded similar DLPS: $269 \mathrm{mGy} \times \mathrm{cm}$ (min: $193 \mathrm{mGy} \times \mathrm{cm}$, max: $403 \mathrm{mGy} \times \mathrm{cm}$, median: $257 \mathrm{mGy} \times \mathrm{cm}-128$ slice $\mathrm{CT}$ ) and $273 \mathrm{mGy} \times \mathrm{cm}$ (min: $170 \mathrm{mGy} \times \mathrm{cm}$, max: $420 \mathrm{mGy} \times \mathrm{cm}$, median: $263 \mathrm{mGy} \times \mathrm{cm}-16$ slice CT); the apparent difference is not statistically significant $(\mathrm{p}=0.682)$. Mean volumes of the examined patients of each CT device are presented in Table 2. Patients who underwent DSHP CT had significantly smaller volumes compared to both of the single source CT groups $\left(18956.3 \mathrm{~cm}^{3}\right.$ vs. $22481.2 \mathrm{~cm}^{3}$ vs. $22133.8 \mathrm{~cm}^{3}$, p $\left.<0.01\right)$. Table 3 shows the volumes in correlation to the individual DLP. Poorest correlation was found for lung volume for the individual groups (range: from $r=0.157$ to $r=0.278$ ) as well as for the average correlation of all of the study groups $(r=0.293)$. The highest correlation was found for "soft tissue and bone volume" $(r=0.763)$ and for the parameter "patient volume" $(r=0.738)$. Mean dose efficiency, as quotient of soft tissue and bone volume and DLP, for the single source groups was $64.5 \mathrm{~cm} 3$ per mGy $\times \mathrm{cm}(128$ slice CT) respectively $61.9 \mathrm{~cm} 3$ per mGy $\times$ cm (16 slice CT, Figure 3). The best mean dose efficiency was observed for the DSHP CT group with $68.5 \mathrm{~cm}^{3}$ per mGy $\times \mathrm{cm}(-11 \%$, DSHP vs. 16 slice CT; Figure 3). The standard deviation of dose efficiency was 8.5 vs. 9.6 vs. $8.4 \mathrm{~cm}^{3}$ per $\mathrm{mGy} \times \mathrm{cm}$.

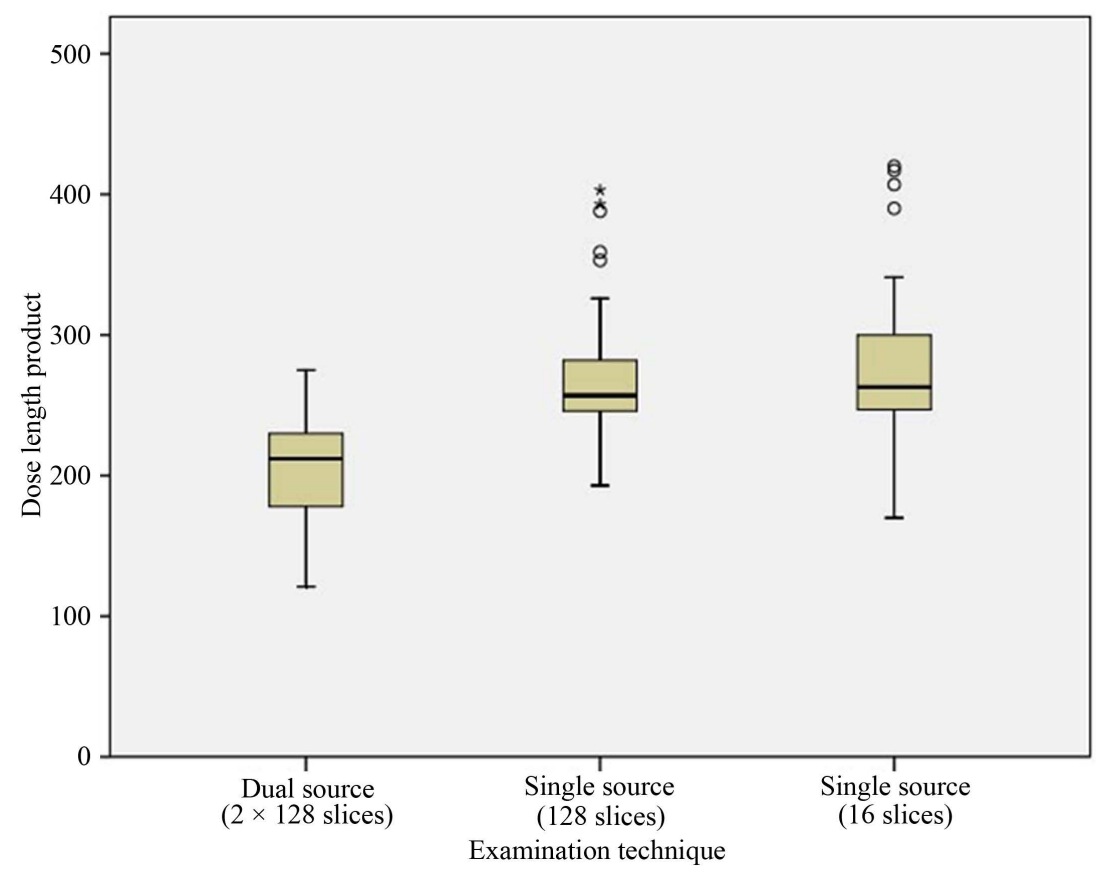

Figure 2. Dose length product (DLP) of the different study groups. The DLP of the dual-source group was significantly lower compared to both of the other techniques $(\mathrm{p}<0.001)$. 


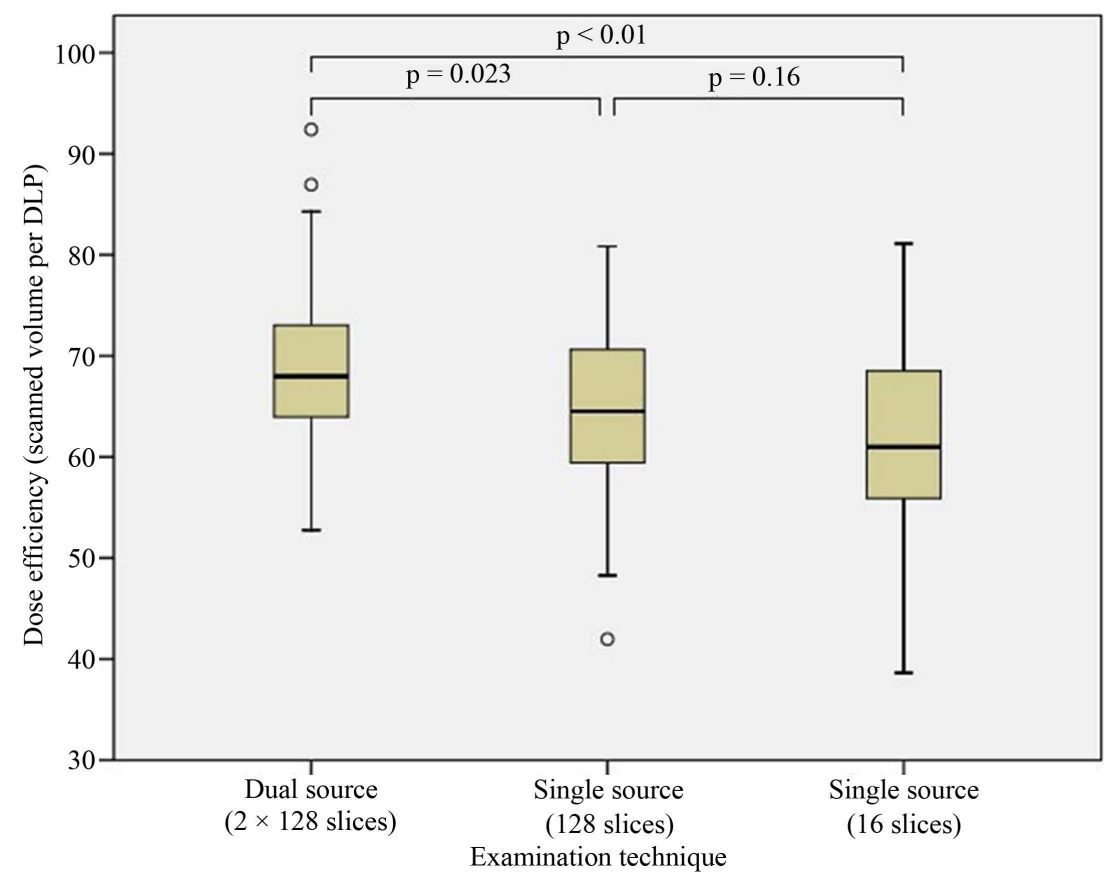

Figure 3. Dose efficiency as a quotient of the measured variable "soft tissue and bone volume" and DLP. The higher the achieved value on the y axis, the better the dose efficiency. The photon yield per scanned volume of the dual-source high-pitch technique is slightly higher, but with statistical significance, than both of the other groups.

Table 2. Measured patient volumes that were examined during thoracic CT. Total patient volume represent the sum of "lung volume" and "soft tissue, bone volume".

\begin{tabular}{cccc}
\hline & Dual-source $(2 \times 128$ slices $)$ & Single-source $(128$ slices $)$ & Single-source (16 slices) \\
\hline Lung volume Mean \pm SD & $4730.8 \mathrm{~cm}^{3} \pm 1271$ & $5411.8 \mathrm{~cm}^{3} \pm 1290$ & $5504.3 \mathrm{~cm}^{3} \pm 1505$ \\
Median & $4590.2 \mathrm{~cm}^{3}$ & $5235.2 \mathrm{~cm}^{3}$ & $5145.6 \mathrm{~cm}^{3}$ \\
Soft tissue, bone volume & $14225.5 \mathrm{~cm}^{3} \pm 2681$ & $17069.4 \mathrm{~cm}^{3} \pm 3274$ & $16629.5 \mathrm{~cm}^{3} \pm 3195$ \\
Mean \pm SD Median & $13908.3 \mathrm{~cm}^{3}$ & $16966.3 \mathrm{~cm}^{3}$ & $16186.8 \mathrm{~cm}^{3}$ \\
Total patient volume & $18956.3 \mathrm{~cm}^{3} \pm 3132$ & $22481.2 \mathrm{~cm}^{3} \pm 3849$ & $22133.8 \mathrm{~cm}^{3} \pm 3934$ \\
Mean \pm SD Median & $18753.9 \mathrm{~cm}^{3}$ & $22126.1 \mathrm{~cm}^{3}$ & $21277.0 \mathrm{~cm}^{3}$ \\
\hline
\end{tabular}

Standard deviation (SD).

Table 3. Spearman's rank correlation coefficient of the measured variables in relation to the dose length product (DLP). The closer the value is to unity, the better the correlation. The measured parameter "soft tissue and bone volume" has the best correlation to the applied radiation dose.

\begin{tabular}{ccccc}
\hline & $\begin{array}{c}\text { Dual-source } \\
(2 \times 128 \text { slices })\end{array}$ & $\begin{array}{c}\text { Single-source } \\
(128 \text { slices })\end{array}$ & $\begin{array}{c}\text { Single-source } \\
(16 \text { slices })\end{array}$ & All study groups \\
\hline Lung volume & 0.157 & 0.179 & 0.278 & 0.293 \\
Soft tissue, bone volume & 0.775 & 0.736 & 0.636 & 0.763 \\
Total patient volume & 0.727 & 0.686 & 0.623 & 0.738 \\
\hline
\end{tabular}

\section{Discussion}

In this study, the radiation exposure of single and dual-source thoracic CT was analyzed with regards to the individual patient anatomy. Therefore, we developed and applied a measurement method to assess the dependence of patient dose, more specifically, the dose-length product (DLP), on patient habitus. By performing mathematical correlations of volumetric analyses to the radiation exposure (DLP) on each patient, a more accurate radia- 
tion performance of the different CT techniques could be assessed.

By comparing plain DLP results and not considering the inter-individual anatomic variants, a 25\% dose benefit in the dual-source high-pitch group could be observed (Figure 2). However, a notable difference among the different CT devices considered is the smaller tissue volume actually irradiated with the dual-source device versus the single-source devices. This is not unexpected, as obese patients cannot be imaged with dual-source scanners because the smaller field of view (FOV) of the second x-ray sources. This constrains patient compatibility to the high pitch mode and leads to a preselection in daily routine. The fact that the average patient volume is about one fifth smaller obviously had to have a large impact on the applied radiation dose that is adjusted by automated tube current modification.

In concordance to basic radiation physics, the most dose dependent factor found in this study relies on $\mathrm{x}$-ray absorption of the parameter "soft tissue and bones" which points validity of performing correlation analyses to the DLP. Thoracic anatomy is special because of differences in anatomy like obesity or barrel chest, which may have significant but contrary effects regarding radiation absorption and consecutively the necessary dose application.

In the current study, the effect of patient body habitus on the volume of tissue actually irradiated and therefore on the radiation dose delivered was evaluated. Dose efficiency was defined as quotient of examined patient volume per DLP, at which the variable "soft tissue and bone volume" was characterized by the highest correlation in each of the single study groups. Considering the proposed variable, benefit of scanned volume per DLP (Dose efficiency) for the 128 slice CT is still significant, yet with an approximated difference of only about $11 \%$ instead of the 25\% mentioned above (Figure 3). Yet, even when regarding different patient anatomy, the dose penalty caused by 16 slice CT is highly significant in comparison to the high-pitch mode. This may rely on technical advantages of modern CT devices such as beam filtration and detector technologies (wider coverage, adaptive collimation) and efficiency of the automated tube current modulation software [11].

Taking patient's anatomy into account, the radiation exposure of DSHP CT still seems to be about $10 \%$ lower than single source CT on the same device. However, Paul et al. compared the organ dose of single and dualsource CT in a phantom study and found an increased radiation burden at similar scan parameters [12]. The results of their thermo-luminescent dosimeter-based organ dose measurements show comparable DLP values for both single and dual-source CT studies, hence with a dose penalty of about $10 \%$ for the DSHP technique. A comparison of the results of their phantom study and those from our current study indicate that tissue doses are essentially the same when performing either dual-source or single-source CT of the chest.

Diagnostic image quality was not part of this study although we want to emphasize all CT examinations were clinically evaluable. It is known that high-pitch dual-source modes acquire images with slightly increased graininess in comparison to single source CT datasets [9] [13] [14]. However, according to the literature the increased image noise does not seem to cause a significant decrease in diagnostic quality [4] [5] [13] [15] [16]. Adaptive image reconstruction algorithms were not available at the time of data acquisition of this study, and these techniques have the potential to reduce image noise and thus radiation dose significantly [17]-[19]. Yet unknown is the value of iterative reconstruction methods in dual-source CT of the thorax.

\subsection{Limitations of the Study}

The manual segmentation process of cutting off the lung parenchyma every $1.5 \mathrm{~cm}$ may cause certain inaccuracies in all measurements (systematic bias). The relative heterogeneous gender distribution within the three study groups may influence the result, since an increase of radiation dose is known in female patients due to breast tissue [20]. Furthermore, still uncertain is the amount of scattered radiation of dual versus single-source CT, which has not yet been evaluated in the literature. Although our model of cutting out soft tissue structures for a more dedicated estimation of radiation exposure, it is not feasible to approximate radiation exposure to single organs. Due to its technical nature the proposed method in this study cannot distinguish between different organs: For once the CT weighted Dose Index is only averaged for each slice and, furthermore, different organs appear on the same slice with an unknown portion of radiation delivered to. Therefore organ dose estimations based on phantom measurements as proposed by the ICRP would be more accurate and therefore method of choice.

\subsection{Conclusion}

In conclusion, both techniques (128 single source and 128 DSHP CT) seem to be comparable in terms of dose 
efficiency; therefore, the dual-source technique should be used whenever non compliance in terms of patient motion is expected. Dose efficiency of the dual-source high-pitch technique is considerably better in comparison to 16 slice CT. Compared to 128 slice single source CT, the dual-source high-pitch mode does not cause any dose penalty when performing chest examinations.

\section{References}

[1] Flohr, T., Stierstorfer, K., Raupach, R., Ulzheimer, S. and Bruder, H. (2004) Performance Evaluation of a 64-Slice CT System with z-Flying Focal Spot. RöFo: Fortschritte auf dem Gebiet der Röntgenstrahlen und der Nuklearmedizin, 176, 1803-1810. http://dx.doi.org/10.1055/s-2004-813717

[2] Flohr, T.G., Leng, S., Yu, L., Aiimendinger, T., Bruder, H., Petersilka, M., Eusemann, C.D., Stierstorfer, K., Schmidt, B. and McCollough, C.H. (2009) Dual-Source Spiral CT with Pitch up to 3.2 and 75 ms Temporal Resolution: Image Reconstruction and Assessment of Image Quality. Medical Physics, 36, 5641-5653. http://dx.doi.org/10.1118/1.3259739

[3] Schulz, B., Jacobi, V., Beeres, M., Bodelle, B., Gruber, T., Lee, C., Bauer, R., Kerl, M., Vogl, T. and Zangos, S. (2012) Quantitative Analysis of Motion Artifacts in High-Pitch Dual-Source Computed Tomography of the Thorax. Journal of Thoracic Imaging, 27, 382-386. http://dx.doi.org/10.1097/RTI.0b013e3182575729

[4] Bamberg, F., Marcus, R., Sommer, W., Schwarz, F., Nikolaou, K., Becker, C.R., Reiser, M.F. and Johnson, T.R.C. (2012) Diagnostic Image Quality of a Comprehensive High-Pitch Dual-Spiral Cardiothoracic CT Protocol in Patients with Undifferentiated Acute Chest Pain. European Journal of Radiology, 81, 3697-3702. http://dx.doi.org/10.1016/j.ejrad.2010.11.032

[5] Lell, M.M., May, M., Deak, P., Alibek, S., Kuefner, M., Kuettner, A., Köhler, H., Achenbach, S., Uder, M.and Radkow, T. (2011) High-Pitch Spiral Computed Tomography: Effect on Image Quality and Radiation Dose in Pediatric Chest Computed Tomography. Investigative Radiology, 46, 116-123. http://dx.doi.org/10.1097/RLI.0b013e3181f33b1d

[6] Kuettner, A., Gehann, B., Spolnik, J., Koch, A., Achenbach, S., Weyand, M., Dittrich, S., Uder, M. and Staatz, G. (2009) Strategies for Dose-Optimized Imaging in Pediatric Cardiac Dual Source CT. RöFo: Fortschritte auf dem Gebiet der Röntgenstrahlen und der Nuklearmedizin, 181, 339-348. http://dx.doi.org/10.1055/s-0028-1109293

[7] Goetti, R., Leschka, S., Boschung, M., Mayer, S., Wyss, C., Stolzmann, P. and Frauenfelder, T. (2012) Radiation Doses from Phantom Measurements at High-Pitch Dual-Source Computed Tomography Coronary Angiography. European Journal of Radiology, 81, 773-779. http://dx.doi.org/10.1016/j.ejrad.2011.01.068

[8] Ertel, D., Lell, M.M., Harig, F., Flohr, T., Schmidt, B. and Kalender, W.A. (2009) Cardiac Spiral Dual-Source CT with High Pitch: A Feasibility Study. European Radiology, 19, 2357-2362. http://dx.doi.org/10.1007/s00330-009-1503-6

[9] Sommer, W.H., Schenzle, J.C., Becker, C.R., Nikolaou, K., Graser, A., Michalski, G., Neumaier, K., Reiser, M.F. and Johnson, T.R.C. (2010) Saving Dose in Triple-Rule-Out Computed Tomography Examination Using a High-Pitch Dual Spiral Technique. Investigative Radiology, 45, 64-71. http://dx.doi.org/10.1097/RLI.0b013e3181c15842

[10] Bauer, R.W., Schell, B., Beeres, M., Wichmann, J.L., Bodelle, B., Vogl, T.J. and Kerl, J.M. (2012) High-Pitch Dual-Source Computed Tomography Pulmonary Angiography in Freely Breathing Patients. Journal of Thoracic Imaging, 27, 376-381. http://dx.doi.org/10.1097/RTI.0b013e318250067e

[11] Harrieder, A., Geyer, L.L., Körner, M., Deak, Z., Wirth, S., Reiser, M. and Linsenmaier, U. (2012) Evaluation of Radiation Dose in 64-Row Whole-Body CT of Multiple Injured Patients Compared to 4-Row CT. RöFo-Fortschritte auf dem Gebiet der Röntgenstrahlen und der Bildgebenden Verfahren, 184, 443-449.

[12] Paul, J., Banckwitz, R., Krauss, B., Vogl, T.J., Maentele, W. and Bauer, R.W. (2012) Estimation and Comparison of Effective Dose (E) in Standard Chest CT by Organ Dose Measurements and Dose-Length-Product Methods and Assessment of the Influence of CT Tube Potential (Energy Dependency) on Effective Dose in a Dual-Source CT. European Journal of Radiology, 81, e507-e512. http://dx.doi.org/10.1016/j.ejrad.2011.06.006

[13] Tacelli, N., Remy-Jardin, M., Flohr, T., Faivre, J.-B., Delannoy, V., Duhamel, A. and Remy, J. (2010) Dual-Source Chest CT Angiography with High Temporal Resolution and High Pitch Modes: Evaluation of Image Quality in 140 Patients. European Radiology, 20, 1188-1196. http://dx.doi.org/10.1007/s00330-009-1638-5

[14] Baumueller, S., Alkadhi, H., Stolzmann, P., Frauenfelder, T., Goetti, R., Schertler, T., Plass, A., Falk, V., Feuchtner, G., et al. (2011) Computed Tomography of the Lung in the High-Pitch Mode: Is Breath Holding Still Required? Investigative Radiology, 46, 240-245. http://dx.doi.org/10.1097/RLI.0b013e3181feee1a

[15] Goetti, R., Baumüller, S., Feuchtner, G., Stolzmann, P., Karlo, C., Alkadhi, H. and Leschka, S. (2010) High-Pitch Dual-Source CT Angiography of the Thoracic and Abdominal Aorta: Is Simultaneous Coronary Artery Assessment Possible? American Journal of Roentgenology, 194, 938-944. http://dx.doi.org/10.2214/AJR.09.3482

[16] Schell, B., Bauer, R.W., Lehnert, T., Kerl, J.M., Hambek, M., May, A., Vogl, T.J. and Mack, M.G. (2011) Low-Dose 
Computed to-Mography of the Paranasal Sinus and Facial Skull Using a High-Pitch Dual-Source System-First Clinical Results. European Radiology, 21, 107-112. http://dx.doi.org/10.1007/s00330-010-1892-6

[17] Mueck, F.G., Michael, L., Deak, Z., Scherr, M.K., Maxien, D., Geyer, L.L., Reiser, M. and Wirth, S. (2013) Upgrade to Iterative Image Reconstruction (IR) in MDCT Imaging: A Clinical Study for Detailed Parameter Optimization beyond Vendor Recommendations Using the Adaptive Statistical Iterative Reconstruction Environment (ASIR) Part 2: The Chest. RöFo-Fortschritte auf dem Gebiet der Röntgenstrahlen und der Bildgebenden Verfahren, 185, 644-654. http://dx.doi.org/10.1055/s-0033-1335152

[18] Kröpil, P., Lanzman, R.S., Walther, C., Röhlen, S., Godehardt, E., Mödder, U. and Cohnen, M. (2010) Dose Reduction and Image Quality in MDCT of the Upper Abdomen: Potential of an Adaptive Post-Processing Filter. RöFoFortschritte auf dem Gebiet der Röntgenstrahlen und der Bildgebenden Verfahren, 182, 248-253. http://dx.doi.org/10.1055/s-0028-1109835

[19] Gosch, D., Stumpp, P., Kahn, T. and Nagel, H.D. (2011) Performance of an Automatic Dose Control System for CT: Anthropomorphic Phantom Studies. RöFo-Fortschritte auf dem Gebiet der Röntgenstrahlen und der Bildgebenden Verfahren, 183, 154-162. http://dx.doi.org/10.1055/s-0029-1245730

[20] Ketelsen, D., Buchgeister, M., Fenchel, M., Thomas, C., Boehringer, N., Tsiflikas, I., Kaempf, M., Syha, R., Claussen, C.D., et al. (2010) Estimation of Radiation Exposure of Prospectively Triggered 128-Slice Computed Tomography Coronary Angiography. RöFo-Fortschritte auf dem Gebiet der Röntgenstrahlen und der Bildgebenden Verfahren, 182, 1105-1109. http://dx.doi.org/10.1055/s-0029-1245812 
Scientific Research Publishing (SCIRP) is one of the largest Open Access journal publishers. It is currently publishing more than 200 open access, online, peer-reviewed journals covering a wide range of academic disciplines. SCIRP serves the worldwide academic communities and contributes to the progress and application of science with its publication.

Other selected journals from SCIRP are listed as below. Submit your manuscript to us via either submit@scirp.org or Online Submission Portal.
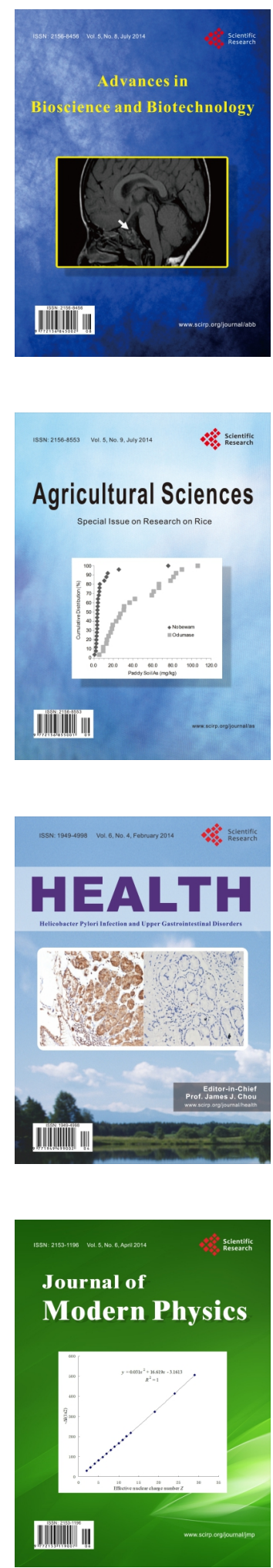
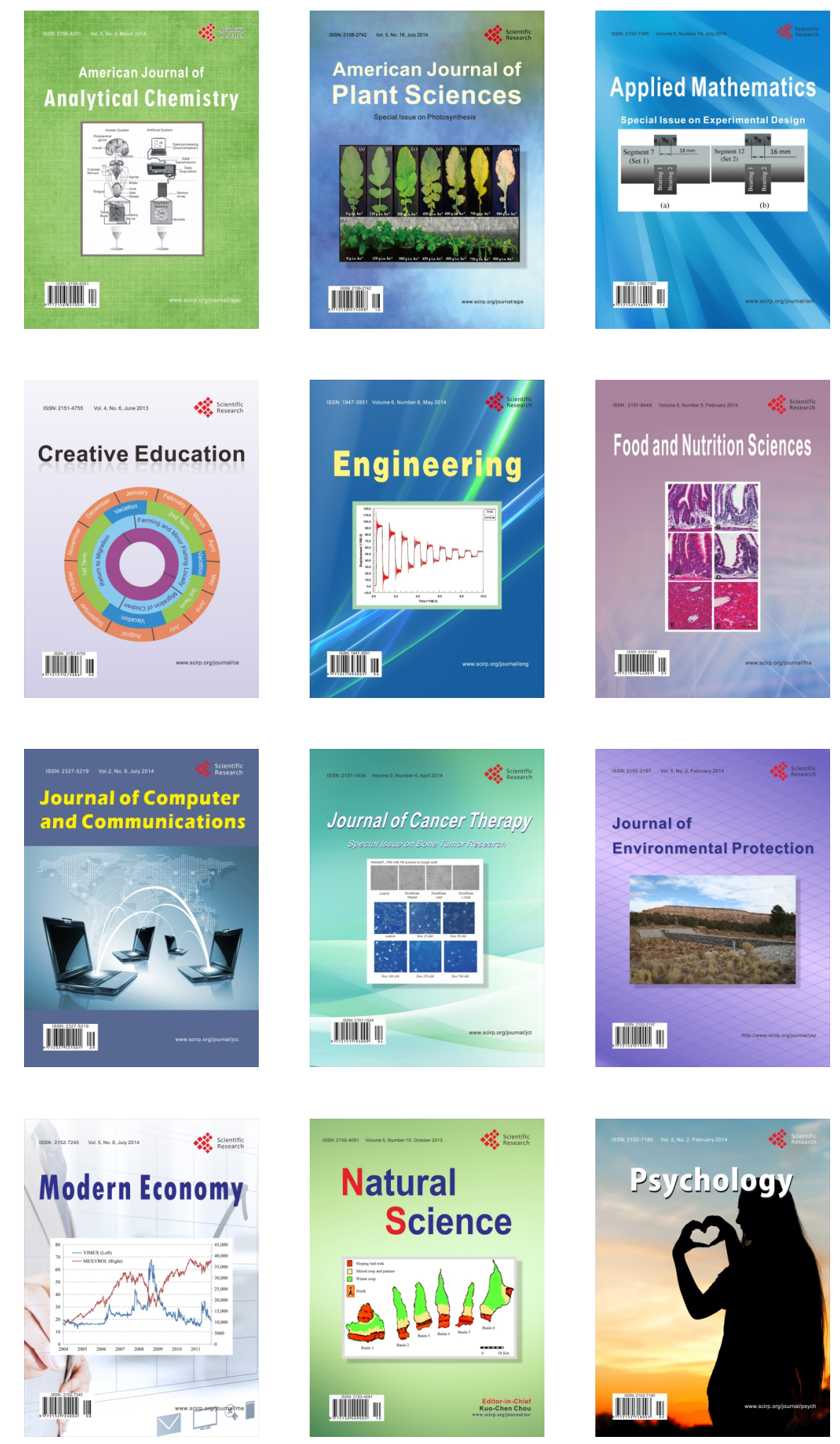